\title{
Synthesis, antioxidant and antimicrobial evaluation of thiazolidinone, azetidinone encompassing indolylthienopyrimidines
}

\author{
ANAND RAGHUNATH SAUNDANE*, MANJUNATHA YARLAKATTI, \\ PRABHAKER WALMIK and VIJAYKUMAR KATKAR \\ Department of Post-Graduate Studies and Research in Chemistry, Gulbarga University, \\ Gulbarga-585 106, India \\ e-mail: arsaundane@rediff.com
}

MS received 26 March 2011; revised 22 July 2011; accepted 8 August 2011

\begin{abstract}
Various 2-amino- $\mathrm{N}^{\prime}-\left\{3-\left(2^{\prime}, 5^{\prime}\right.\right.$-disubstituted-1H-indol-3'-yl)methylene $\}-4,5$-dimethylthieno-3carbohydrazides (3) synthesized by condensation of 2-amino-4,5-dimethyl thiophene-3-carbohydrazide (2) with 2,5- disubstituded indole-3-carboxaldehyde (1). The Schiff's base (3) on cyclocondensation with acetic anhydride and triethyl orthoformate afforded thienopyrimidine analogues (4) and (7), respectively. Compounds 4 or 7 on cyclization with thioglycolic acid and chloroacetyl chloride gave thiazolidin-4-ones (5) or (8) and azitidin-2-ones (6) or (9) respectively. The structures of these newly synthesized compounds have been established on the basis of their spectral data and elemental analysis. Some of the compounds exhibited promising antioxidant and antimicrobial activities.
\end{abstract}

Keywords. Indole; thienopyrimidine; thiazolidin-4-one; azetidin-2-one; antioxidant; antimicrobial activities.

\section{Introduction}

The complex sequence of cellular and molecular changes that take place during cancer formation are mediated by the different endogenous and exogenous stimuli. ${ }^{1}$ Among endogenous stimuli are intermediates of oxygen reduction, i.e., oxygen free radicals (OFR), or more generally, reactive oxygen species (ROS), which interact with DNA, forming various aducts. OFRs are important in the pathogenesis of many different diseases. ${ }^{2-5}$ ROS are also involved in the processes of aging. In food, rancidity is one of the major concerns and is mainly related to oxidative degradation of polyunsaturated fatty acids. For years, antioxidants have been used to prevent the degradation of food. ${ }^{6}$ Phenolic derivatives are one of the most effective and commonly used antioxidants. These derivatives slow down the degradation of food ingredients by inhibiting their oxidation. ${ }^{7,8}$ Among this family of compounds, both synthetic antioxidants for example BHT, BHA, TBHQ and natural ones such as tocopherols, phenolic acids, and herbal extracts are used to protect against oxidative degradation. Although synthetic antioxidants

*For correspondence have shown good efficiency, their use has been limited because of their possible detrimental effect on human health. ${ }^{6}$ As a consequence, there is a growing interest in the development of new antioxidants that are based on natural components and with low toxicity.

Heterocyclic compounds are highly ranked among pharmaceutically important natural and synthetic materials. The remarkable ability of heterocyclic nuclei to serve as both biomimetics and active pharmacophores has largely contributed to their unique value as traditional key elements of numerous drugs. It is well known that, indole derivative extensively present in natural products, are very important substances for their medicinal and biological aspects. Malatonin (MLT) ${ }^{9}$ is a highly conserved molecule that it acts as a free radical scavenger and a broad spectrum antioxidant. ${ }^{10}$ It is known to be a potent in vitro antioxidant as well as powerful in vivo radical scavenger. Indole nucleus is frequently found in medicinal chemistry and is considered as privileged scaffolds. Indole analogues constitute an important class of therapeutic agents in medicinal chemistry including anticancer, ${ }^{11}$ antioxidant, ${ }^{12}$ antirheumatoidal, ${ }^{13}$ anti-HIV, ${ }^{14}$ and also play a vital role in the immune system. ${ }^{15,16}$ Many indole derivatives considered as the most potent scavengers of free radicals. ${ }^{17}$

The thiophene ring is bioisosteric replacement for the phenyl group broadly present in active drugs, the thiophene core exists in many natural and synthetic 
pharmaceuticals, ${ }^{18,19}$ tuberculosis ${ }^{20}$ and antimicrobial drugs. ${ }^{21}$

The molecular manipulation of promising lead compounds is still a major line of approach to develop new drugs. It involves an effort to combine the separate pharmacophoric groups of similar activity into one compound, thus making structural changes in the biological activity. As reported earlier the thiazolidinone ring present in a large number of biologically active molecules of different pharmacological classes exhibited different activities. The historical importance of thiazolidine derivative, i.e., the development of penicillin which shows the presence of thiazoline ring. There has been substantial interest in the chemistry of thiazolidin4-one ring systems, which is the core structure in a variety of synthetic pharmaceuticals with a broad spectrum of biological activity, ${ }^{22}$ such as anti-mycobacterial, ${ }^{23}$ antifungal, ${ }^{24}$ anti-cancer, ${ }^{25}$ anti-tuberculosis, ${ }^{26}$ anticonvulsant, ${ }^{27}$ anti-edematous, ${ }^{28}$ anti-diarrhea, ${ }^{29}$ anti$\mathrm{HIV},{ }^{30,31}$ anti-platelet-activating factor, ${ }^{32}$ antidiabetic, ${ }^{33}$ antihistaminic, ${ }^{34}$ cyclooxygenase inhibitors, lipoxygenase inhibitors, ${ }^{35}$ anti-inflammatory and analgesic ${ }^{36}$ activity. In addition, a large number of antibiotics contain the 2-azetidinone (commonly known as $\beta$-lactam) moiety ${ }^{37}$ such as penicillin, cephalosporin and carbapenem. It is also associated with a variety of therapeutic activities. ${ }^{38-42}$

Due to the diversified nature of indole, thienopyrimidine, thiazolidin-4-one and 2-azetidinones which render them useful substance in drug research. In continuation of our search for novel biologically active indole derivatives, ${ }^{43,44}$ in this paper we report the synthesis, antioxidant and antibacterial activities of the title compounds and its derivatives.

\section{Experimental}

All the reagents were obtained commercially and used by further purification. Melting points were determined by an open capillary method and are uncorrected. The IR (KBr) spectra were recorded with a PerkinElmer spectrum one FT-IR spectrometer. The ${ }^{1} \mathrm{HNMR}$ $(500 \mathrm{MHz})$ and ${ }^{13} \mathrm{C}$ NMR $(125 \mathrm{MHz})\left(\mathrm{DMSO}-d_{6}\right)$ spectra recorded with an Bruker NMR $(500 \mathrm{Mz})$ and the chemical shifts were expressed in ppm ( $\delta$ scale) downfield from TMS. Mass spectra were recorded with a JEOL GCMATE II GC-MS mass spectrometer. Elemental analysis carried out using Flash EA1112 series elemental analyzer.

\subsection{2-Amino-4,5-dimethyl-thiophene-3-carbohydrazide (2)}

2-Amino-4,5-dimethyl-thiophene-3-carbohydrazide (2) was prepared by following reported method. ${ }^{45}$

2.2 2-Amino-4,5-dimethyl-3-\{ $N^{1}-\left[\left(2^{\prime}-\right.\right.$ phenyl-5'-substituted 1H-indol-3'-yl)methylene]\}thieno-3-carbohydrazides $(3 a-c)$

A mixture of hydrazide (2) $(0.001 \mathrm{~mol})$ and the respective 2,-phenyl-5-substituted indole-3-caroxaldehydes ${ }^{46}$ $(\mathbf{1} \mathbf{a}-\mathbf{c})(0.001 \mathrm{~mol})$ in ethanol $(30 \mathrm{ml})$ was refluxed for $3 \mathrm{~h}$ and then left to cool. The solid formed was collected by filtration and recrystallized from ethanol to give compounds $\mathbf{3 a}-\mathbf{c}$.

2.2a 2-Amino-4,5-dimethyl-3-\{ $N^{1}-\left[\left(2^{\prime}-\right.\right.$ phenyl-5'-chloro1H-indol-3'-yl)methylene]\} thieno-3-carbohydrazide (3a): Yellow powder, Yield $0.31 \mathrm{~g}(72 \%)$, m. p. $125-126^{\circ} \mathrm{C}$; IR $(\mathrm{KBr}) v \mathrm{~cm}^{-1} 3404\left(\mathrm{NH}_{2}\right), 3301$ (indole $\left.\mathrm{NH}\right), 3170$ $(\mathrm{NH}), 1645(\mathrm{CO}), 1598(\mathrm{C}=\mathrm{N}) ;{ }^{1} \mathrm{H}$ NMR $(500 \mathrm{MHz}$, DMSO-d $\left._{6}\right) \delta 11.5(\mathrm{~s}, 1 \mathrm{H}$, indole $\mathrm{NH}), 9.9(\mathrm{~s}, 1 \mathrm{H}, \mathrm{NH})$, $8.9(\mathrm{~s}, 1 \mathrm{H}, \mathrm{CH}=\mathrm{N}), 7.1-8.0\left(\mathrm{~m}, 10 \mathrm{H}, 8 \mathrm{ArH}\right.$ and $\left.\mathrm{NH}_{2}\right)$, $2.7\left(\mathrm{~s}, 3 \mathrm{H}, 5-\mathrm{CH}_{3}\right), 2.3\left(\mathrm{~s}, 3 \mathrm{H}, 4-\mathrm{CH}_{3}\right) ;{ }^{13} \mathrm{C} \mathrm{NMR}$ $\left(125 \mathrm{MHz}, \mathrm{DMSO}-\mathrm{d}_{6}\right): \delta 13.4,14.1,114.1,121.5$, $122.5,125.6,126.7,128.5,129.3,130.1,133.2,134.3$, 134.6, 134.9, 138.2, 140.2, 142.6, 142.7, 168.2, 171.2; EI-MS; m/z 422, 424; Anal. calcd. for $\mathrm{C}_{22} \mathrm{H}_{19} \mathrm{~N}_{4} \mathrm{OSCl}$ : C 62.56; H, 4.50; N, 13.27. Found: C,62.77; H4.33; N, 13.51 .

2.2b 2-Amino-4,5-dimethyl-3-\{ $N^{1}-\left[\left(2^{\prime}-\right.\right.$ phenyl-5'-methy3$1 H$-indol-3'-yl)methylene]\}thieno-3-carbohydrazide (3b): Yellow powder, Yield $0.281 \mathrm{~g}(70 \%)$, m. p. $144-145^{\circ} \mathrm{C}$; IR $(\mathrm{KBr}) v \mathrm{~cm}^{-1} 3406\left(\mathrm{NH}_{2}\right), 3309$ (indole $\left.\mathrm{NH}\right), 3176$ (NH), $1645(\mathrm{CO}) 1599(\mathrm{C}=\mathrm{N})$; ${ }^{1} \mathrm{H}$ NMR $(500 \mathrm{MHz}$, DMSO-d $\left._{6}\right) \delta 11.4(\mathrm{~s}, 1 \mathrm{H}$, indole NH), $9.8(\mathrm{~s}, 1 \mathrm{H}, \mathrm{NH})$, $8.9(\mathrm{~s}, 1 \mathrm{H}, \mathrm{CH}=\mathrm{N}), 7.0-8.0\left(\mathrm{~m}, 10 \mathrm{H}, 8 \mathrm{ArH}\right.$ and $\left.\mathrm{NH}_{2}\right)$, $2.8\left(\mathrm{~s}, 3 \mathrm{H}, 5-\mathrm{CH}_{3}\right), 2.5\left(\mathrm{~s}, 3 \mathrm{H}, 5^{\prime}-\mathrm{CH}_{3}\right), 2.2(\mathrm{~s}, 3 \mathrm{H}, 4-$ $\left.\mathrm{CH}_{3}\right) ;{ }^{13} \mathrm{C}$ NMR (125 M Hz, DMSO-d 6 ): $\delta 13.5,14.3$, 24.2, 114.5, 122.0, 123.1, 125.1, 126.9, 128.8, 129.7, 130.4, 133.6, 134.3, 134.6, 134.9, 140.0, 140.7, 142.0, 143.1, 168.6, 171.6; Anal. calcd. for $\mathrm{C}_{23} \mathrm{H}_{22} \mathrm{~N}_{4} \mathrm{OS}$ : C 68.66; H, 5.47; N, 13.93. Found: C, 68.47; H, 5.29; N, 14.05 .

$2.2 \mathrm{c}$ 2-Amino-4,5-dimethyl-3- $\left\{N^{1}-\left[\left(2^{\prime}-\right.\right.\right.$ phenyl-5'- $1 H$ indol-3'-yl)methylene]\}thieno-3-carbohydrazide $(\mathbf{3 c})$ : Yellow powder, Yield $0.275 \mathrm{~g}(71 \%)$, m. p. $130-131^{\circ} \mathrm{C}$; IR $(\mathrm{KBr}) v \mathrm{~cm}^{-1} 3402\left(\mathrm{NH}_{2}\right), 3305$ (indole $\left.\mathrm{NH}\right), 3172$ $(\mathrm{NH}), 1648(\mathrm{CO}) 1602(\mathrm{C}=\mathrm{N}) ;{ }^{1} \mathrm{H}$ NMR $(500 \mathrm{MHz}$, 
DMSO- $\left.\mathrm{d}_{6}\right) \delta 11.3(\mathrm{~s}, 1 \mathrm{H}$, indole $\mathrm{NH}), 9.8(\mathrm{~s}, 1 \mathrm{H}, \mathrm{NH})$, $8.8(\mathrm{~s}, 1 \mathrm{H}, \mathrm{CH}=\mathrm{N}), 7.1-7.9\left(\mathrm{~m}, 11 \mathrm{H}, 9 \mathrm{ArH}\right.$ and $\left.\mathrm{NH}_{2}\right)$, $2.7\left(\mathrm{~s}, 3 \mathrm{H}, 5-\mathrm{CH}_{3}\right), 2.4\left(\mathrm{~s}, 3 \mathrm{H}, 4-\mathrm{CH}_{3}\right)$; Anal. calcd. for $\mathrm{C}_{22} \mathrm{H}_{20} \mathrm{~N}_{4} \mathrm{OS}: \mathrm{C}$ 68.04; H, 5.14; N, 14.43. Found: C, $68.13 ; \mathrm{H}, 5.27$; N, 14.29.

2.3 2,5,6-Trimethyl-3-[(2'-phenyl-5'-substituted $1 H$ indol-3'-yl)methyleneamino] thieno[2,3-d]pyrimidin$4(3 H)$-ones $(\mathbf{4 a}-\boldsymbol{c})$

Compound 3 (0.001 mol) in acetic anhydride $(18 \mathrm{ml})$ were heated under reflux for $6 \mathrm{~h}$ and cooled to room temperature. The precipitated solid was collected and recrystallized from 1,4-dioxane.

$2.3 a \quad 2,5,6$-Trimethyl-3-[(2'-phenyl-5'-chloro-1H-indol3'-yl)methyleneamino]-thieno[2,3-d]pyrimidin-4(3H)one $(4 a)$ : Yellow powder, Yield $0.29 \mathrm{~g}(65 \%)$, m. p. $185-186^{\circ} \mathrm{C}$; IR $(\mathrm{KBr}) v \mathrm{~cm}^{-1} 3301$ (indole $\left.\mathrm{NH}\right), 1648$ (CO), $1598(\mathrm{C}=\mathrm{N}) ;{ }^{1} \mathrm{H}$ NMR $\left(500 \mathrm{MHz}, \mathrm{DMSO}_{-} \mathrm{d}_{6}\right) \delta$ $11.3(\mathrm{~s}, 1 \mathrm{H}$, indole $\mathrm{NH}), 9.1(\mathrm{~s}, 1 \mathrm{H}, \mathrm{CH}=\mathrm{N}), 7.1-7.9$ $(\mathrm{m}, 8 \mathrm{H}, \mathrm{ArH}), 3.2\left(\mathrm{~s}, 3 \mathrm{H}, 2-\mathrm{CH}_{3}\right), 2.8\left(\mathrm{~s}, 3 \mathrm{H}, 6-\mathrm{CH}_{3}\right)$, $2.4\left(\mathrm{~s}, 3 \mathrm{H}, 5-\mathrm{CH}_{3}\right) ;{ }^{13} \mathrm{C}$ NMR (125 M Hz, DMSO-d 6 ): $\delta 13.2,14.3,16.2,114.2,121.4,122.5,125.7,126.6$, $128.4,129.0,130.4,130.8,130.9,133.2,134.4,134.6$, 134.9, 142.1, 142.5, 143.8, 150.6, 172.8; EI-MS; m/z 446, 448; Anal. calcd. for $\mathrm{C}_{24} \mathrm{H}_{19} \mathrm{~N}_{4} \mathrm{OSCl}$ : C 64.57; $\mathrm{H}$, 4.26; N, 12.56. Found: C, 64.71; H, 4.41; N, 12.31 .

$2.3 b \quad 2,5,6-T r i m e t h y l-3-\left[\left(2^{\prime}-\right.\right.$ phenyl-5'-methyl-1H-indol3'-yl)methyleneamino]-thieno[2,3-d]pyrimidin-4(3H)one (4b): Pale yellow powder, Yield $0.276 \mathrm{~g}(65 \%)$, m. p. $162-163^{\circ} \mathrm{C}$; IR $(\mathrm{KBr}) v \mathrm{~cm}^{-1} 3305$ (indole $\mathrm{NH}$ ), $1646(\mathrm{CO}), 1595(\mathrm{C}=\mathrm{N}) ;{ }^{1} \mathrm{H}$ NMR $(500 \mathrm{MHz}, \mathrm{DMSO}-$ $\left.\mathrm{d}_{6}\right) \delta 11.4(\mathrm{~s}, 1 \mathrm{H}$, indole $\mathrm{NH}), 9.0(\mathrm{~s}, 1 \mathrm{H}, \mathrm{CH}=\mathrm{N})$, 7.0-7.9 (m, 8H, ArH), 3.3 (s, 3H, 2- $\left.\mathrm{CH}_{3}\right), 2.8$ (s, 3H, $\left.6-\mathrm{CH}_{3}\right), 2.5\left(\mathrm{~s}, 3 \mathrm{H}, 5^{\prime}-\mathrm{CH}_{3}\right), 2.3\left(\mathrm{~s}, 3 \mathrm{H}, 5-\mathrm{CH}_{3}\right) ;{ }^{13} \mathrm{C}$ NMR (125 M Hz, DMSO-d $\left.{ }_{6}\right): \delta 13.3,14.2,16.6,24.5$, $114.3,121.6,122.8,125.9,126.9,128.2,129.1,130.0$, $130.5,131.1,133.4,134.5,134.9,135.2,142.3,142.5$, 143.5, 150.8, 172.3; Anal. calcd. for $\mathrm{C}_{25} \mathrm{H}_{22} \mathrm{~N}_{4} \mathrm{OS}$ : C 70.42; H, 5.16; N, 13.14. Found: C, 70.55; H, 5.21; N, 13.05 .

2.3c 2,5,6-Trimethyl-3-[(2'-phenyl-5'-1H-indol-3'yl)methyleneamino]-thieno[2,3-d]pyrimidin-4(3H)-one (4c): Pale yellow powder, Yield 0.26 g $(63 \%)$, m. p. 179$180^{\circ} \mathrm{C}$; IR (KBr) $v \mathrm{~cm}^{-1} 3307$ (indole $\mathrm{NH}$ ), 1652 (CO), $1599(\mathrm{C}=\mathrm{N}) ;{ }^{1} \mathrm{H}$ NMR $\left(500 \mathrm{MHz}, \mathrm{DMSO}-\mathrm{d}_{6}\right) \delta 11.3$ $(\mathrm{s}, 1 \mathrm{H}$, indole $\mathrm{NH}), 9.1(\mathrm{~s}, 1 \mathrm{H}, \mathrm{CH}=\mathrm{N}), 7.1-8.0(\mathrm{~m}$, $9 \mathrm{H}, \mathrm{ArH}), 3.3\left(\mathrm{~s}, 3 \mathrm{H}, 2-\mathrm{CH}_{3}\right), 2.7\left(\mathrm{~s}, 3 \mathrm{H}, 6-\mathrm{CH}_{3}\right), 2.2$ (s, 3H, 5- $\mathrm{CH}_{3}$ ); EI-MS; Anal. calcd. for $\mathrm{C}_{22} \mathrm{H}_{20} \mathrm{~N}_{4} \mathrm{OS}$ : C 69.90; H, 4.85; N, 13.59. Found: C, 70.03; H, 4.97; $\mathrm{N}, 13.45$.

2.4 2,5,6-Trimethyl-3-[2-(2'-phenyl-5'-substituted $1 \mathrm{H}$ indol-3'-yl)-4-oxothiazolidin-3-yl]thieno[2,3-d]pyrimidin$4(3 H)$-ones $(\mathbf{5} \boldsymbol{a}-\boldsymbol{c})$

To a solution of compound $\mathbf{4}$ in methanol containing catalytic amount of anhydrous zinc chloride, thioglycolic acid $(0.001 \mathrm{~mol})$ was added drop-wise at room temperature and the reaction mixture was refluxed for $10 \mathrm{~h}$ the excess methanol was distilled off, the residue was cooled to room temperature and decomposed in ice cold water. The product that separated was filtered, washed with water, dried and recrystallized from ethanol.

2.4a 2,5,6-Trimethyl-3-[2-(2'-phenyl-5'-chloro-1H-indol3-yl)-4-oxothiazolidin-3-yl]thieno[2,3-d]pyrimidin-4(3H)one (5a): Yellow crystals, Yield $0.374 \mathrm{~g}(72 \%)$, m. p. 201-202 ${ }^{\circ}$; IR (KBr) $v \mathrm{~cm}^{-1} 3313$ (indole NH), 1681 $\left(\mathrm{CH}_{2} \mathrm{CO}\right), 1645$ (CO); ${ }^{1} \mathrm{H}$ NMR $(500 \mathrm{MHz}, \mathrm{DMSO}-$ $\left.\mathrm{d}_{6}\right) \delta 11.6(\mathrm{~s}, 1 \mathrm{H}$, indole $\mathrm{NH}), 10.0(\mathrm{~s}, 1 \mathrm{H}, \mathrm{CH}-\mathrm{N})$, 7.0-7.9 (m, 8H, ArH), 4.1 (s, 2H, $\left.\mathrm{CH}_{2} \mathrm{CO}\right), 3.2$ (s, 3H, 2- $\left.\mathrm{CH}_{3}\right), 2.7\left(\mathrm{~s}, 3 \mathrm{H}, 6-\mathrm{CH}_{3}\right), 2.3\left(\mathrm{~s}, 3 \mathrm{H}, 5-\mathrm{CH}_{3}\right) ;{ }^{13} \mathrm{C}$ NMR (125 M Hz, DMSO-d $\left.\mathrm{d}_{6}\right): \delta 12.8,13.7,16.7,35.7$, $107.1,113.8,121.5,122.6,125.4,126.4,129.0,129.3$, $130.2,130.5,130.8,133.1,134.2,134.5,134.9,143.5$, 143.8, 149.9,. 168.7, 172.7; EI-MS; m/z 520, 522; Anal. calcd. for $\mathrm{C}_{26} \mathrm{H}_{21} \mathrm{~N}_{4} \mathrm{O}_{2} \mathrm{~S}_{2} \mathrm{Cl}$ : C 60.00; H, 4.04; N, 10.77. Found: C, 60.21; H, 4.32; N, 10.52 .

$2.4 \mathrm{~b} \quad$ 2,5,6-Trimethyl-3-[2-(2'-phenyl-5'methyl-1H-indol3-yl)-4-oxothiazolidin-3-yl]thieno[2,3-d]pyrimidin-4(3H)one (5b): Pale yellow crystals, Yield $0.35 \mathrm{~g}(70 \%)$, m. p. $191-192^{\circ} \mathrm{C}$; IR (KBr) $v \mathrm{~cm}^{-1} 3308$ (indole $\mathrm{NH}$ ), $1685\left(\mathrm{CH}_{2} \mathrm{CO}\right), 1647$ (CO); ${ }^{1} \mathrm{H}$ NMR $(500 \mathrm{MHz}$, DMSO $\left.\mathrm{d}_{6}\right) \delta 11.5(\mathrm{~s}, 1 \mathrm{H}$, indole $\mathrm{NH}), 10.1(\mathrm{~s}, 1 \mathrm{H}$, CH-N), 7.1-8.1 (m, 8H, ArH), 4.0 (s, 2H, $\mathrm{CH}_{2} \mathrm{CO}$ ), 3.1 (s, 3H, 2- $\left.\mathrm{CH}_{3}\right), 2.6\left(\mathrm{~s}, 3 \mathrm{H}, 6-\mathrm{CH}_{3}\right), 2.5\left(\mathrm{~s}, 3 \mathrm{H}, 5^{\prime}-\mathrm{CH}_{3}\right)$, $2.2\left(\mathrm{~s}, 3 \mathrm{H}, 5-\mathrm{CH}_{3}\right) ;{ }^{13} \mathrm{C}$ NMR $\left(125 \mathrm{M} \mathrm{Hz}, \mathrm{DMSO}-\mathrm{d}_{6}\right)$ : $\delta$ 13.1, 14.1, 16.8, 24.3, 35.5, 107.3, 113.7, 121.4, $122.7,125.4,126.5,129.1,129.4,130.2,130.6,130.7$, 133.2, 134.1, 134.5, 134.7, 143.4, 143.7, 149.8, 168.5, 172.8; Anal. calcd. for $\mathrm{C}_{27} \mathrm{H}_{24} \mathrm{~N}_{4} \mathrm{O}_{2} \mathrm{~S}_{2}$ : C 64.80; H, 4.80; N, 11.12. Found: C, 64.97; H, 4.57; N, 11.37.

$2.4 \mathrm{c}$ 2,5,6-Trimethyl-3-[2-(2'-phenyl-1H-indol-3-yl)4-oxothiazolidin-3-yl]thieno[2,3-d]pyrimidin-4(3H)one $(5 \mathrm{c})$ : Pale yellow powder, Yield $0.315 \mathrm{~g}(65 \%)$, 
m. p. $186-187^{\circ} \mathrm{C}$; IR $(\mathrm{KBr}) v \mathrm{~cm}^{-1} 3310$ (indole $\mathrm{NH}$ ), $1683\left(\mathrm{CH}_{2} \mathrm{CO}\right), 1649(\mathrm{CO}) ;{ }^{1} \mathrm{H}$ NMR $(500 \mathrm{MHz}$, DMSO- $\left.\mathrm{d}_{6}\right) \delta 11.4(\mathrm{~s}, 1 \mathrm{H}$, indole $\mathrm{NH}), 10.0(\mathrm{~s}, 1 \mathrm{H}$, CH-N), 7.0-8.0 (m, 9H, ArH), 4.1 (s, 2H, $\left.\mathrm{CH}_{2} \mathrm{CO}\right), 3.2$ (s, 3H, 2- $\left.\mathrm{CH}_{3}\right), 2.6\left(\mathrm{~s}, 3 \mathrm{H}, 6-\mathrm{CH}_{3}\right), 2.3\left(\mathrm{~s}, 3 \mathrm{H}, 5-\mathrm{CH}_{3}\right)$; Anal. calcd. for $\mathrm{C}_{26} \mathrm{H}_{22} \mathrm{~N}_{4} \mathrm{O}_{2} \mathrm{~S}_{2}: \mathrm{C} 64.20 ; \mathrm{H}, 4.53 ; \mathrm{N}$, 11.52. Found: C, 64.37; H, 4.67; N, 11.37.

2.5 2,5,6-Trimethyl-3-[3-chloro-2-(2'-phenyl-5'-substituted $1 \mathrm{H}$-indol-3'-yl)-4-oxoazetidin-1-yl]-thieno[2, 3-d]pyrimidin-4(3H)-ones $(\boldsymbol{6} \boldsymbol{a}-\boldsymbol{c})$

A mixture of compound $4(0.001 \mathrm{~mol})$ and triethyl amine $(0.001 \mathrm{~mol})$ was dissolved in methanol $(20 \mathrm{ml})$ and cooled to $0^{\circ} \mathrm{C}$. To this well cooled solution, chloroacetylchloride $(0.001 \mathrm{~mol})$ was added drop-wise during $30 \mathrm{~min}$ with stirring at $0^{\circ} \mathrm{C}$. The reaction mixture was further stirred for $1 \mathrm{~h}$ and refluxed for $12 \mathrm{~h}$. The triethyl amine hydrochloride salt formed was removed by filtration. The filtrate was concentrated to its half volume, cooled to room temperature and poured on to crushed ice. The product was obtained was filtered, washed with water and recrystallized from ethanol.

2.5a 2,5,6-Trimethyl-3-[3-chloro-2-(2'-phenyl-5'-chloro1H-indol-3'-yl)-4-o xoazetidin-1-yl]-thieno[2,3-d]pyrimidin4(3H)-one (6a): Brown powder, Yield $0.36 \mathrm{~g} \mathrm{(69 \% ),}$ m. p. $210-211^{\circ} \mathrm{C}$; IR (KBr) $v \mathrm{~cm}^{-1} 3301$ (indole $\mathrm{NH}), 1720$ (CHCO), 1645 (CO); ${ }^{1} \mathrm{H}$ NMR (500 MHz, DMSO- $\left.\mathrm{d}_{6}\right) \delta 11.5(\mathrm{~s}, 1 \mathrm{H}$, indole $\mathrm{NH}), 10.0(\mathrm{~d}, 1 \mathrm{H}$, CH-N), 6.9-7.8 (m, 8H, ArH), $5.6(\mathrm{~d}, 1 \mathrm{H}, \mathrm{CHCl}), 3.2$ (s, 3H, 2- $\left.\mathrm{CH}_{3}\right), 2.7\left(\mathrm{~s}, 3 \mathrm{H}, 6-\mathrm{CH}_{3}\right), 2.3\left(\mathrm{~s}, 3 \mathrm{H}, 5-\mathrm{CH}_{3}\right)$; ${ }^{13} \mathrm{C}$ NMR (125 M Hz, DMSO-d $\left.\mathrm{d}_{6}\right): \delta 13.2,14.2,16.7$, $82.5,106.3,113.1,113.7,121.5,122.5,125.6,126.1$, $128.1,129.1,130.4,130.5,130.7,134.1,134.6,134.9$, 142.4, 143.8, 150.1, 160.6, 172.7; EI-MS; m/z 522, 524, 526; Anal. calcd. for $\mathrm{C}_{26} \mathrm{H}_{20} \mathrm{~N}_{4} \mathrm{O}_{2} \mathrm{SCl}_{2}$ : C, 59.77; H, 3.83; N, 10.73. Found: C, 59.99; H, 3.71; N, 10.95 .

$2.5 \mathrm{~b}$ 2,5,6-Trimethyl-3-[3-chloro-2-(2'-phenyl-5'-methyl1H-indol-3'-yl)-4-oxoazetidin-1-yl]-thieno[2,3-d]pyrimidin4(3H)-one ( $\boldsymbol{6} \boldsymbol{b})$ : Brown powder, Yield $0.342 \mathrm{~g}(68 \%)$, m. p. $214-215^{\circ} \mathrm{C}$; IR $(\mathrm{KBr}) \vee \mathrm{cm}^{-1} 3309$ (indole $\mathrm{NH}), 1725$ (CHCO), 1653 (CO); ${ }^{1} \mathrm{H}$ NMR (500 MHz, DMSO $\left.\mathrm{d}_{6}\right) \delta 11.4(\mathrm{~s}, 1 \mathrm{H}$, indole $\mathrm{NH}), 10.1(\mathrm{~d}, 1 \mathrm{H}$, CH-N), 7.0-7.9 (m, 8H, ArH), $5.7(\mathrm{~d}, 1 \mathrm{H}, \mathrm{CHCl}), 3.3$ (s, 3H, 2- $\left.\mathrm{CH}_{3}\right), 2.7$ (s, 3H, 6- $\left.-\mathrm{CH}_{3}\right), 2.4$ (s, 3H, 5'- $\mathrm{CH}_{3}$ ), $2.2\left(\mathrm{~s}, 3 \mathrm{H}, 5-\mathrm{CH}_{3}\right) ;{ }^{13} \mathrm{C}$ NMR $\left(125 \mathrm{M} \mathrm{Hz}, \mathrm{DMSO}-\mathrm{d}_{6}\right)$ : $\delta 13.1,14.5,16.8,24.8,82.3,105.2,106.2,113.2$, $113.8,121.6,122.4,125.5,126.3,128.2,129.1,130.5$, $130.6,130.8,134.0,134.5,134.8,142.4,143.5,160.5$,
172.8; Anal. calcd. for $\mathrm{C}_{27} \mathrm{H}_{23} \mathrm{~N}_{4} \mathrm{O}_{2} \mathrm{SCl}$ : C, 64.54; $\mathrm{H}$, 4.58; N, 11.16. Found: C, 64.71; H, 4.43; N, 11.29.

$2.5 \mathrm{c}$ 2,5,6-Trimethyl-3-[3-chloro-2-(2'-phenyl-1H-indol3-yl)-4-oxoazetidin-1-yl]-thieno[2,3-d]pyrimidin-4(3H)one $(6 \mathrm{c})$ : Brown powder, Yield $0.3 \mathrm{~g}(62 \%)$, m. p. 199-200 ${ }^{\circ}$; IR (KBr) $v \mathrm{~cm}^{-1} 3305$ (indole $\left.\mathrm{NH}\right), 1728$ (CHCO), 1649 (CO); ${ }^{1} \mathrm{H}$ NMR (500 MHz, DMSO$\left.\mathrm{d}_{6}\right) \delta 11.5(\mathrm{~s}, 1 \mathrm{H}$, indole $\mathrm{NH}), 10.0(\mathrm{~d}, 1 \mathrm{H}, \mathrm{CH}-\mathrm{N})$, 6.9-8.0 (m, 9H, ArH), $5.6(\mathrm{~d}, 1 \mathrm{H}, \mathrm{CHCl}), 3.3(\mathrm{~s}, 3 \mathrm{H}$, 2- $\left.\mathrm{CH}_{3}\right), 2.7\left(\mathrm{~s}, 3 \mathrm{H}, 6-\mathrm{CH}_{3}\right), 2.2\left(\mathrm{~s}, 3 \mathrm{H}, 5-\mathrm{CH}_{3}\right)$; Anal. calcd. for $\mathrm{C}_{26} \mathrm{H}_{21} \mathrm{~N}_{4} \mathrm{O}_{2} \mathrm{SCl}$ : C, 63.93; H, 4.30; N, 11.48. Found: C, 63.87; H, 4.17; N, 11.61.

2.6 5,6-Dimethyl-3-[(2'-phenyl-5'-substituted 1H-indol3'-yl)methyleneamino]-thieno[2,3-d]pyrimidin-4(3H)ones $(7 \boldsymbol{a}-\boldsymbol{c})$

A mixture of $3 \mathbf{a}-\mathbf{c}(0.001)$ and triethyl orthoformate $(5 \mathrm{ml})$ in acetic anhydride $(10 \mathrm{ml})$ was heated under reflux for $7 \mathrm{~h}$ and then allowed to cool. The product separated was collected and recrystallized from ethanol.

2.6a 5,6-Dimethyl-3-[(2'-phenyl-5'-chloro- $1 \mathrm{H}$-indol3'-yl)methyleneamino]-thieno[2,3-d]pyrimidin-4(3H)one $(7 a)$ : Yellow powder, Yield $0.315 \mathrm{~g}(73 \%), \mathrm{m} . \mathrm{p}$. $175-176^{\circ} \mathrm{C}$; IR (KBr) $v \mathrm{~cm}^{-1} 3301$ (indole $\left.\mathrm{NH}\right), 1645$ (CO), $1597(\mathrm{C}=\mathrm{N}) ;{ }^{1} \mathrm{H}$ NMR (500 MHz, DMSO-d $\left.\mathrm{d}_{6}\right) \delta$ $11.3(\mathrm{~s}, 1 \mathrm{H}$, indole $\mathrm{NH}), 9.0(\mathrm{~s}, 1 \mathrm{H}, \mathrm{CH}=\mathrm{N}), 8.5(\mathrm{~s}$, $1 \mathrm{H}$, pyrimidin- $\mathrm{H}), 7.0-7.9(\mathrm{~m}, 8 \mathrm{H}, \operatorname{ArH}), 2.7$ (s, 3H, 6- $\left.\mathrm{CH}_{3}\right), 2.3\left(\mathrm{~s}, 3 \mathrm{H}, 5-\mathrm{CH}_{3}\right) ;{ }^{13} \mathrm{C}$ NMR $(125 \mathrm{M} \mathrm{Hz}$, DMSO$\left.-\mathrm{d}_{6}\right): \delta 13.4,14.2,114.0,121.4,122.0,125.6$, 126.2 , 129.0, 129.2, 130.1, 130.6, 130.9, 133.1, 134.2, $134.6,134.9,142.1,142.9,143.8,152.1,172.9$; EIMS; m/z 432, 434; Anal. calcd. for $\mathrm{C}_{23} \mathrm{H}_{17} \mathrm{~N}_{4} \mathrm{OSCl}$ : C, 63.89; H, 3.93; N, 12.96. Found: C, 63.71; H, 4.10; N, 12.85 .

$2.6 \mathrm{~b}$ 5,6-Dimethyl-3-[(2'-phenyl-5'-methyl-1H-indol3'-yl)methyleneamino]-thieno[2,3-d]pyrimidin-4(3H)one $(7 \boldsymbol{b})$ : Yellow powder, Yield $0.288 \mathrm{~g}(70 \%), \mathrm{m} . \mathrm{p}$. $169-171^{\circ} \mathrm{C}$; IR (KBr) $v \mathrm{~cm}^{-1} 3305$ (indole $\left.\mathrm{NH}\right), 1645$ (CO), $1594(\mathrm{C}=\mathrm{N}) ;{ }^{1} \mathrm{H}$ NMR $\left(500 \mathrm{MHz}, \mathrm{DMSO}-\mathrm{d}_{6}\right)$ $\delta 11.4(\mathrm{~s}, 1 \mathrm{H}$, indole $\mathrm{NH}), 9.1(\mathrm{~s}, 1 \mathrm{H}, \mathrm{CH}=\mathrm{N}), 8.6$ (s, $1 \mathrm{H}$, pyrimidin- $\mathrm{H}), 7.1-8.0(\mathrm{~m}, 8 \mathrm{H}, \mathrm{ArH}), 2.8(\mathrm{~s}$, $\left.3 \mathrm{H}, 6-\mathrm{CH}_{3}\right), 2.4\left(\mathrm{~s}, 3 \mathrm{H}, 5^{\prime}-\mathrm{CH}_{3}\right), 2.2\left(\mathrm{~s}, 3 \mathrm{H}, 5-\mathrm{CH}_{3}\right)$; ${ }^{13} \mathrm{C}$ NMR $\left(125 \mathrm{M} \mathrm{Hz}\right.$, DMSO-d $\left.{ }_{6}\right): \delta 13.5,14.1,24.3$, $114.2,121.3,122.5,125.8,126.3,129.1,129.4,130.3$, 130.8, 131.2, 133.5, 134.4, 134.7, 134.8, 142.3, 142.6, 143.6, 152.4, 172.6; Anal. calcd. for $\mathrm{C}_{24} \mathrm{H}_{20} \mathrm{~N}_{4} \mathrm{OS}$ : C, 
69.90; H, 4.85; N, 13.59. Found: C, 69.73; H, 4.98; N, 13.67.

2.6c 5,6-Dimethyl-3-[(2'-phenyl-5'-1H-indol-3'-yl)methyleneamino]-thieno[2,3-d]pyrimidin-4(3H)-one (7c): Pale yellow powder, Yield $0.286(72 \%)$, m. p. 158$159^{\circ} \mathrm{C}$; IR (KBr) $v \mathrm{~cm}^{-1} 3307$ (indole $\mathrm{NH}$ ), 1653 (CO), $1599(\mathrm{C}=\mathrm{N})$; ${ }^{1} \mathrm{H}$ NMR (500 MHz, DMSO$\left.\mathrm{d}_{6}\right) \delta 11.3(\mathrm{~s}, 1 \mathrm{H}$, indole $\mathrm{NH}), 9.0(\mathrm{~s}, 1 \mathrm{H}, \mathrm{CH}=\mathrm{N})$, 8.5 (s, $1 \mathrm{H}$, pyrimidin- $\mathrm{H}), 7.1-8.1(\mathrm{~m}, 9 \mathrm{H}, \operatorname{ArH}), 2.7$ (s, 3H, 6- $\left.\mathrm{CH}_{3}\right), 2.2\left(\mathrm{~s}, 3 \mathrm{H}, 5-\mathrm{CH}_{3}\right)$; Anal. calcd. for $\mathrm{C}_{23} \mathrm{H}_{18} \mathrm{~N}_{4} \mathrm{OS}: \mathrm{C}, 69.35 ; \mathrm{H}, 4.52 ; \mathrm{N}, 14.07$. Found: $\mathrm{C}$, 69.60; H, 4.69; N, 14.20.

2.7 5,6-Dimethyl-3-[2-(2'-phenyl-5'-substituted 1H-indol3'-yl)-4-oxothiazolidin-3-yl]thieno[2,3-d]pyrimidin-4(3H)ones $(8 \boldsymbol{a}-\boldsymbol{c})$

These compounds were synthesized following the procedure given for compounds $\mathbf{5}$ a-c.

2.7a 5,6-Dimethyl-3-[2-(2'-phenyl-5'-chloro-1H-indol3-yl)-4-oxothiazolidin-3-yl]thieno[2,3-d]pyrimidin4(3H)-one (8a): Pale yellow flakes, Yield $0.330 \mathrm{~g}$ (72\%), m. p. $215-216^{\circ} \mathrm{C}$; IR (KBr) $v \mathrm{~cm}^{-1} 3301$ (indole $\mathrm{NH}), 1701\left(\mathrm{CH}_{2} \mathrm{CO}\right), 1645$ (CO); ${ }^{1} \mathrm{H}$ NMR $(500 \mathrm{MHz}$, DMSO- $\left._{6}\right) \delta 11.5(\mathrm{~s}, 1 \mathrm{H}$, indole $\mathrm{NH}), 10.0(\mathrm{~s}, 1 \mathrm{H}$, CH-N), 8.7 (s, 1H, pyrimidin- $\mathrm{H}), 7.1-8.0(\mathrm{~m}, 8 \mathrm{H}$, $\mathrm{ArH}), 4.2$ (s, $2 \mathrm{H}, \mathrm{CH}_{2} \mathrm{CO}$ ), 2.7 (s, 3H, 6- $\left.\mathrm{CH}_{3}\right), 2.3$ (s, $\left.3 \mathrm{H}, 5-\mathrm{CH}_{3}\right) ;{ }^{13} \mathrm{C}$ NMR $\left(125 \mathrm{M} \mathrm{Hz}, \mathrm{DMSO}-\mathrm{d}_{6}\right): \delta 13.4$, $14.3,35.8,107.1,113.9,121.6,122.5,125.6,126.3$, $129.0,129.3,130.2,130.5,130.9,133.0,134.3,134.6$, 134.8, 142.3, 143.6, 152.3. 168.8, 172.8; EI-MS; m/z 506, 508; Anal. calcd. for $\mathrm{C}_{25} \mathrm{H}_{19} \mathrm{~N}_{4} \mathrm{O}_{2} \mathrm{~S}_{2} \mathrm{Cl}$ : C, 59.29; H, 3.74; N, 11.07. Found: C, 59.42; H, 3.51; N, 11.29.

2.7b 5,6-Dimethyl-3-[2-(2'-phenyl-5'-methyl-1H-indol3-yl)-4-oxothiazolidin-3-yl]thieno[2,3-d]pyrimidin4(3H)-one $(\boldsymbol{8 b})$ : Yellow flakes, Yield $0.305 \mathrm{~g}(65 \%)$, m. p. $205-206^{\circ} \mathrm{C}$; IR $(\mathrm{KBr}) v \mathrm{~cm}^{-1} 3310$ (indole $\mathrm{NH}$ ), $1705\left(\mathrm{CH}_{2} \mathrm{CO}\right), 1649$ (CO); ${ }^{1} \mathrm{H}$ NMR $(500 \mathrm{MHz}$, DMSO $\left.-\mathrm{d}_{6}\right) \quad \delta 11.4(\mathrm{~s}, 1 \mathrm{H}$, indole $\mathrm{NH}), 10.1(\mathrm{~s}$, $1 \mathrm{H}, \mathrm{CH}-\mathrm{N}), 8.6(\mathrm{~s}, 1 \mathrm{H}$, pyrimidin- $\mathrm{H}), 7.2-8.1$ (m, $8 \mathrm{H}, \mathrm{ArH}), 4.3\left(\mathrm{~s}, 2 \mathrm{H}, \mathrm{CH}_{2} \mathrm{CO}\right), 2.8\left(\mathrm{~s}, 3 \mathrm{H}, 6-\mathrm{CH}_{3}\right)$, $2.4\left(\mathrm{~s}, 3 \mathrm{H}, 5 /-\mathrm{CH}_{3}\right), 2.3\left(\mathrm{~s}, 3 \mathrm{H}, 5-\mathrm{CH}_{3}\right) ;{ }^{13} \mathrm{C} \mathrm{NMR}$ $\left(125 \mathrm{M} \mathrm{Hz}, \mathrm{DMSO}-\mathrm{d}_{6}\right): \delta 13.3,14.2,24.3,35.8,107.1$, $113.7,121.4,122.7,125.8,126.5,129.1,129.4,130.4$, $130.7,130.9,133.2,134.2,134.6,134.8,142.6,143.8$, 152.5, 168.8, 172.8; Anal. calcd. for $\mathrm{C}_{26} \mathrm{H}_{22} \mathrm{~N}_{4} \mathrm{O}_{2} \mathrm{~S}_{2}$ : C, 64.20; H, 4.53; N, 11.52. Found: C, 64.35; H, 4.32; N, 11.67. 2.7c 5,6-Dimethyl-3-[2-(2'-phenyl-1H-indol-3-yl)-4oxothiazolidin-3-yl]thieno[2,3-d]pyrimidin-4(3H)-one $(8 c)$ : Pale yellow powder, Yield $0.292(62 \%)$, m. p. 189-190 C; IR (KBr) $v \mathrm{~cm}^{-1} 3307$ (indole $\left.\mathrm{NH}\right), 1707$ $\left(\mathrm{CH}_{2} \mathrm{CO}\right), 1651(\mathrm{CO}) ;{ }^{1} \mathrm{H}$ NMR (500 MHz, DMSO$\left.\mathrm{d}_{6}\right) \quad \delta 11.5(\mathrm{~s}, 1 \mathrm{H}$, indole $\mathrm{NH}), 10.1(\mathrm{~s}, 1 \mathrm{H}, \mathrm{CH}-\mathrm{N})$, 8.5 (s, 1H, pyrimidin- $\mathrm{H}), 7.1-8.1(\mathrm{~m}, 9 \mathrm{H}, \mathrm{ArH}), 4.2$ (s, $2 \mathrm{H}, \mathrm{CH}_{2} \mathrm{CO}$ ), 2.9 (s, 3H, 6- $\left.\mathrm{CH}_{3}\right), 2.3\left(\mathrm{~s}, 3 \mathrm{H}, 5-\mathrm{CH}_{3}\right)$; Anal. calcd. for $\mathrm{C}_{25} \mathrm{H}_{20} \mathrm{~N}_{4} \mathrm{O}_{2} \mathrm{~S}_{2}: \mathrm{C}, 63.56 ; \mathrm{H}, 4.24 ; \mathrm{N}$, 11.86. Found: C, 63.29; H, 4.37; N, 11.69.

2.8 5,6-Dimethyl-3-(3-chloro-2-(2'-phenyl-5'-substituted $1 \mathrm{H}$-indol-3-yl)-4-oxoazetidin-1-yl)thieno[2,3-d]pyrimidin-4(3H)-ones (9 a-c)

These compounds were synthesized by following the procedure reported for compounds $\mathbf{6} \mathbf{a}-\mathbf{c}$.

2.8a 5,6-Dimethyl-3-[3-chloro-2-(2'-phenyl-5'-chloro1H-indol-3'-yl)-4-oxoazetidin-1-yl]-thieno[2,3-d]pyrimidin4(3H)-one (9a): Yellow flakes, Yield $0.283 \mathrm{~g} \mathrm{(59 \% ),}$ m. p. $231-232^{\circ} \mathrm{C}$; IR (KBr) $v \mathrm{~cm}^{-1} 3301$ (indole $\mathrm{NH}), 1735$ (CHCO), 1645 (CO); ${ }^{1} \mathrm{H}$ NMR (500 MHz, DMSO- $\left._{6}\right) \delta 11.5(\mathrm{~s}, 1 \mathrm{H}$, indole $\mathrm{NH}), 10.0(\mathrm{~d}, 1 \mathrm{H}, \mathrm{CH}-$ $\mathrm{N}), 8.6(\mathrm{~s}, 1 \mathrm{H}$, pyrimidine-H), 6.9-7.8 $(\mathrm{m}, 8 \mathrm{H}, \mathrm{ArH})$, $5.5(\mathrm{~d}, 1 \mathrm{H}, \mathrm{CHCl}), 2.7$ (s, 3H, 6- $\left.\mathrm{CH}_{3}\right), 2.2$ (s, 3H, 5$\left.\mathrm{CH}_{3}\right) ;{ }^{13} \mathrm{C}$ NMR $\left(500 \mathrm{M} \mathrm{Hz}, \mathrm{DMSO}-\mathrm{d}_{6}\right): \delta 12.9,14.1$, $82.4,106.2,113.8,121.4,122.4,125.5,126.2,128.2$, 129.2, 130.2, 130.4, 130.9, 133.2, 134.2, 134.7, 134.9, 142.4, 143.7, 152.4, 160.6, 172.8; EI-MS; m/z 508, 510, 512; Anal. calcd. for $\mathrm{C}_{25} \mathrm{H}_{18} \mathrm{~N}_{4} \mathrm{O}_{2} \mathrm{SCl}_{2}$ : C, 59.05; H, 3.54; N, 11.02. Found: C, 59.21; H, 3.69; N, 11.20.

$2.8 \mathrm{~b}$ 5,6-Dimethyl-3-[3-chloro-2-(2'-phenyl-5'-methyl1H-indol-3'-yl)-4-oxoazetidin-1-yl]-thieno[2,3-d]pyrimidin4(3H)-one $(\mathbf{9 b})$ : Yellow powder, Yield $0.282(59 \%)$, m. p. $223-224^{\circ} \mathrm{C}$; IR (KBr) $v \mathrm{~cm}^{-1} 3315$ (indole $\mathrm{NH}), 1730$ (CHCO), 1654 (CO); ${ }^{1} \mathrm{H}$ NMR $(500 \mathrm{MHz}$, DMSO- $\left._{6}\right) \delta 11.4(\mathrm{~s}, 1 \mathrm{H}$, indole $\mathrm{NH}), 10.1(\mathrm{~d}, 1 \mathrm{H}$, $\mathrm{CH}-\mathrm{N}), 8.5(\mathrm{~s}, 1 \mathrm{H}$, pyrimidine-H), $6.8-7.8(\mathrm{~m}, 8 \mathrm{H}$, $\mathrm{ArH}), 5.6(\mathrm{~d}, 1 \mathrm{H}, \mathrm{CHCl}), 2.7\left(\mathrm{~s}, 3 \mathrm{H}, 6-\mathrm{CH}_{3}\right), 2.5$ (s, $\left.3 \mathrm{H}, 5^{\prime}-\mathrm{CH}_{3}\right), 2.3\left(\mathrm{~s}, 3 \mathrm{H}, 5-\mathrm{CH}_{3}\right) ;{ }^{13} \mathrm{C} \mathrm{NMR}(500 \mathrm{M}$ $\left.\mathrm{Hz}, \mathrm{DMSO}_{-} \mathrm{d}_{6}\right): \delta 13.1,14.2,24.5,82.5,106.2,113.7$, $121.5,122.5,125.7,126.3,128.3,129.1,130.1,130.6$, $130.7,133.4,134.3,134.8,134.9,142.5,143.9,152.6$, 160.7, 172.7; Anal. calcd. for $\mathrm{C}_{26} \mathrm{H}_{21} \mathrm{~N}_{4} \mathrm{O}_{2} \mathrm{SCl}$ : C, 63.93; H, 4.30; N, 11.48. Found: C, 63.78; H, 4.51; N, 11.29 .

2.8c 5,6-Dimethyl-3-[3-chloro-2-(2'-phenyl-5'-1H-indol-3yl)-4-oxoazetidin-1-yl]-thieno[2,3-d]pyrimidin-4(3H)-one (9c): Yellow powder, Yield $0.26 \mathrm{~g}(55 \%)$, m. p. 
198-199 ${ }^{\circ} \mathrm{C}$; IR (KBr) $v \mathrm{~cm}^{-1} 3313$ (indole $\mathrm{NH}$ ), 1727 (CHCO), 1653 (CO); ${ }^{1} \mathrm{H}$ NMR (500 MHz, DMSO$\left.\mathrm{d}_{6}\right) \delta 11.3(\mathrm{~s}, 1 \mathrm{H}$, indole $\mathrm{NH}), 10.2(\mathrm{~d}, 1 \mathrm{H}, \mathrm{CH}-\mathrm{N}), 8.5$ (s, 1H, pyrimidine- $\mathrm{H}), 6.8-7.9(\mathrm{~m}, 9 \mathrm{H}, \mathrm{ArH}), 5.7(\mathrm{~d}$, $1 \mathrm{H}, \mathrm{CHCl}), 2.8\left(\mathrm{~s}, 3 \mathrm{H}, 6-\mathrm{CH}_{3}\right), 2.3\left(\mathrm{~s}, 3 \mathrm{H}, 5-\mathrm{CH}_{3}\right)$; Anal. calcd. for $\mathrm{C}_{25} \mathrm{H}_{19} \mathrm{~N}_{4} \mathrm{O}_{2} \mathrm{SCl}$ : C, 63.29; H, 4.01; N, 11.81. Found: C, 63.52; H, 4.22; N, 11.67.

\section{Result and discussion}

In the present investigation, we have synthesized fused thienopyrimidines linked to position-3 of indole nucleus. The synthetic route to achieve the target compounds was given in the scheme 1. First, 2-amino4,5-dimethyl thiophene-3-charbohydrazide (2) was prepared by following literature method. ${ }^{45}$ This on reaction with hydrazine hydrate gave compound (2). Compound (2) on condensation with 2.5-disubstituted 1H-indole-3-carboxaldehydes ${ }^{46}$ (1) afforded 2-amino$\mathrm{N}^{\prime}$-\{3-(2'-phenyl-5'-substituted $1 \mathrm{H}$-indol-3'-yl)methylene $\}$ 4,5-dimethylthieno-3-carbohydrazides (3). Formation of compound (3) was confirmed by its IR, ${ }^{1} \mathrm{H}$ NMR, ${ }^{13} \mathrm{C}$ NMR and mass spectrum studies. In IR spectrum of compound (3a), various bands appeared at 3404, 3301, 3170,1645 and $1597 \mathrm{~cm}^{-1}$ were due to $\mathrm{NH}_{2}$, indole $\mathrm{NH}, \mathrm{NH}, \mathrm{C}=\mathrm{O}$ and $\mathrm{C}=\mathrm{N}$ functions, respectively. In ${ }^{1} \mathrm{H}$ NMR spectrum of compound (3a) exhibited various signals at $\delta 11.5(\mathrm{~s}, 1 \mathrm{H}$, indole $\mathrm{NH}), 9.9(\mathrm{~s}, 1 \mathrm{H}$, $\mathrm{NH}), 8.9(\mathrm{~s}, 1 \mathrm{H}, \mathrm{CH}=\mathrm{N}), 7.1-8.0(\mathrm{~m}, 10 \mathrm{H}, 8-\mathrm{ArH}$ and $\left.\mathrm{NH}_{2}\right), 2.7\left(\mathrm{~s}, 3 \mathrm{H}, 5-\mathrm{CH}_{3}\right)$ and $2.3\left(\mathrm{~s}, 3 \mathrm{H}, 4-\mathrm{CH}_{3}\right)$. The two distinctive signals at $\delta 142.6$ and 171.2 due to the $\mathrm{CH}=\mathrm{N}$ and amide carbonyl in its ${ }^{13} \mathrm{C}$ NMR confirmed the formation of compound 3a. Where as in mass spectrum, compound 3a exhibited isotopic molecular ion peaks at 422 and 424 confirms the formation of 3a. Compound $\mathbf{3}$ on cyclization with acetic anhydride yielded thienopyrimidine derivatives (4). Structural confirmation of compound $\mathbf{4 a}$ was done using IR, ${ }^{1} \mathrm{H}$ NMR, ${ }^{13} \mathrm{C}$ NMR and mass spectra. The IR spectrum showed characteristic absorption bands at 3301, 1648 and $1598 \mathrm{~cm}^{-1}$ due to indole $\mathrm{NH}, \mathrm{C}=\mathrm{O}$ and $\mathrm{C}=\mathrm{N}$ functions respectively and $\mathrm{NH}_{2}$ and $\mathrm{NH}$ functions were disappeared. In ${ }^{1} \mathrm{H}$ NMR spectrum, various signals resonated at $\delta 11.3(\mathrm{~s}, 1 \mathrm{H}$, indole $\mathrm{NH}), 9.1(\mathrm{~s}, 1 \mathrm{H}$,

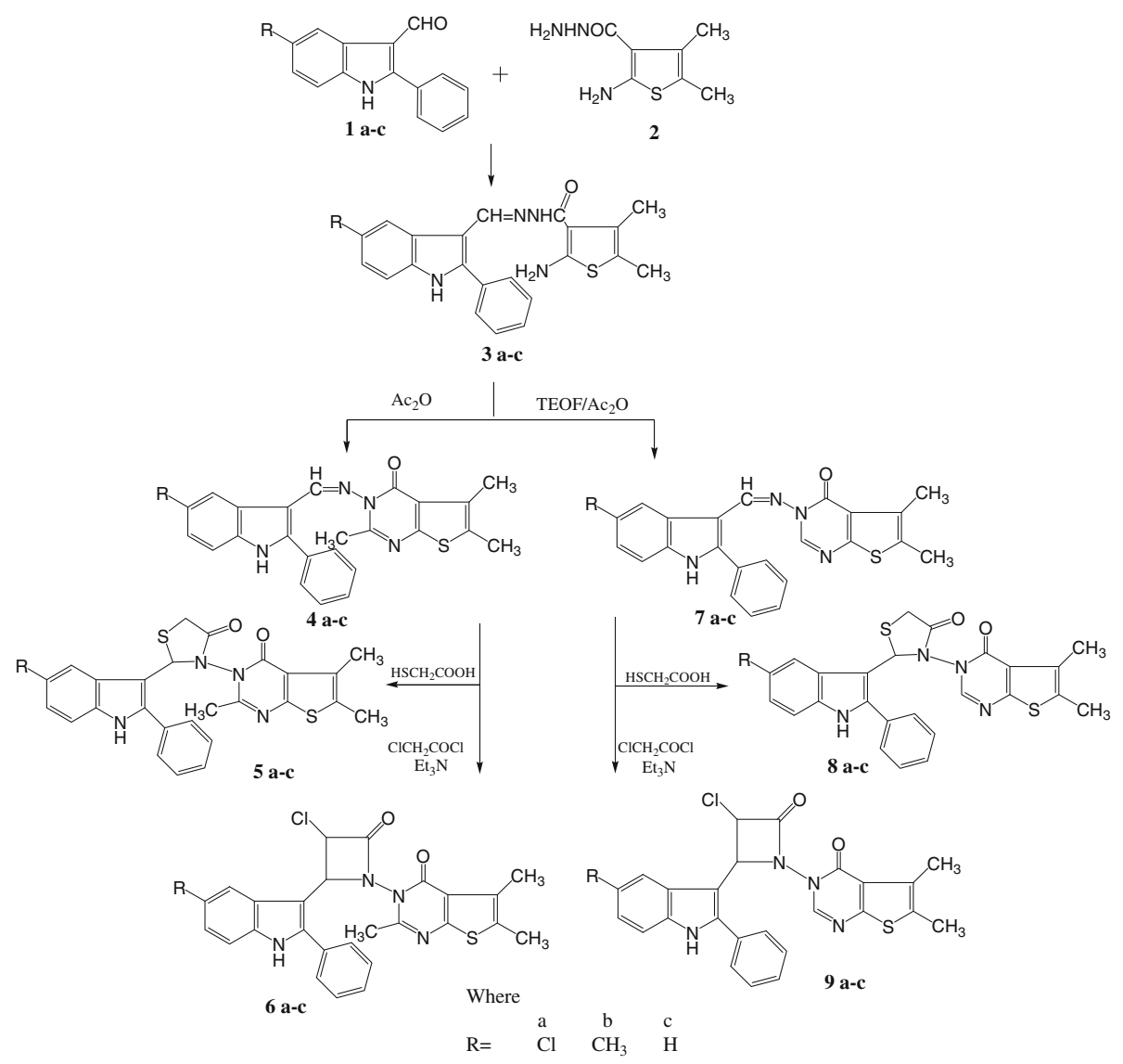

Scheme 1. Synthesis of compounds 5a-c, 8a-c and 5a-c, 9a-c from 3a-c. 
$\mathrm{CH}=\mathrm{N}), 7.1-7.9(\mathrm{~m}, 8 \mathrm{H}, \mathrm{ArH}), 3.2\left(\mathrm{~s}, 3 \mathrm{H}, \mathrm{CH}_{3}\right), 2.8$ (s, $\left.3 \mathrm{H}, 6-\mathrm{CH}_{3}\right)$ and $2.4\left(\mathrm{~s}, 3 \mathrm{H}, 5-\mathrm{CH}_{3}\right)$. The new peaks in its ${ }^{13} \mathrm{C}$ NMR at $\delta 16.2$ and 150.6 appeared due to the methyl group at 2-position of pyrimidothiophene $\mathrm{C}_{2}$ of pyrimidine system. In mass spectrum, $4 \mathbf{a}$ exhibited isotopic molecular ion peaks at 446 and 448 confirms the formation of $\mathbf{4 a}$. Cyclization of compound (4) with thioglycolic acid afforded thiazolidin-4-one derivatives (5). 5a Exhibited various absorption bands in its IR spectrum at 3313,1681 and $1645 \mathrm{~cm}^{-1}$ due to indole $\mathrm{NH}, \mathrm{CH}_{2} \mathrm{CO}$ and $\mathrm{C}=\mathrm{O}$ functions, respectively. In ${ }^{1} \mathrm{H}$ NMR spectrum, various signals at $\delta 11.6(\mathrm{~s}$, $1 \mathrm{H}$, indole $\mathrm{NH}), 10.0$ (s, 1H, CH-N), 7.0-7.9 (m. 8H, $\mathrm{ArH}), 4.1$ (s, $\left.2 \mathrm{H}, \mathrm{CH}_{2} \mathrm{CO}\right), 3.2\left(\mathrm{~s}, 3 \mathrm{H}, 2-\mathrm{CH}_{3}\right), 2.7$ (s, $\left.3 \mathrm{H}, 6-\mathrm{CH}_{3}\right)$ and $2.3\left(\mathrm{~s}, 3 \mathrm{H}, 5-\mathrm{CH}_{3}\right)$ were appeared. ${ }^{13} \mathrm{CNMR}$ spectrum, the new signals at $\delta 35.7$ and 107.1 were resonated due to the $\mathrm{CH}$ and $\mathrm{CH}_{2}$ carbon of thiazolidine system. The mass spectrum of compound 5a exhibited isotopic molecular ion peaks at 520 and 522 confirms the formation of 5a. Also, compounds (4) on treatment with chloroacetylchloride in triethylamine gave azetidin-2-ones (6). Compound $\mathbf{6 a}$ in its IR spectrum showed characteristic absorption bands at 3301,1720 and 1645 due to indole $\mathrm{NH}, \mathrm{CHCO}$ and $\mathrm{C}=\mathrm{O}$ functions, respectively. In its ${ }^{1} \mathrm{H}$ NMR spectrum, 6a showed the absence of $\mathrm{NH}_{2}$ and $\mathrm{NH}$ signals and presence of signals at $11.5(\mathrm{~s}, 1 \mathrm{H}$, indole $\mathrm{NH}), 10.0(\mathrm{~d}$, $1 \mathrm{H}, \mathrm{CH}-\mathrm{N}), 6.9-7.8(\mathrm{~m}, 8 \mathrm{H}, \mathrm{ArH}), 3.2\left(\mathrm{~s}, 3 \mathrm{H}, 2-\mathrm{CH}_{3}\right)$, $2.7\left(\mathrm{~s}, 3 \mathrm{H}, 6-\mathrm{CH}_{3}\right), 2.3\left(\mathrm{~s}, 3 \mathrm{H}, 5-\mathrm{CH}_{3}\right)$ and appearance of new doublet signal at $5.6(\mathrm{~d}, 1 \mathrm{H}, \mathrm{CH}-\mathrm{Cl})$ confirms the presence of lactum ring. Further, the signals at $\delta$ 82.5 and 160.6 corresponding to the $\mathrm{CH}$ and $\mathrm{CH}-\mathrm{Cl}$ of azetidinone moiety. Compound $\mathbf{6 a}$ exhibited isotopic molecular ion peaks at 522, 524 and 526 confirms the formation of lacum ring.

On the other hand, compound $\mathbf{3}$ ion reaction with triethyhlorthoformate in actic anhydride gave thienopyrimidines (7). Compound (7) on reaction with thioglycolic acid afforded the indole derivative of thiazolidin-4-ones (8). Further, compound (7) on cyclocondensation with chloacetylchloride, produced azetidin-2-ones (9). Structure of compounds 7, 8 and 9 were confirmed by their spectral studies (see experimental section).

\section{Biological activities}

\subsection{Reducing power assay}

The reducing power of the synthesized compounds was determined according to the method of Oyaizu. ${ }^{47}$ Different concentrations of the samples $(25-100 \mu \mathrm{g} / \mathrm{ml})$

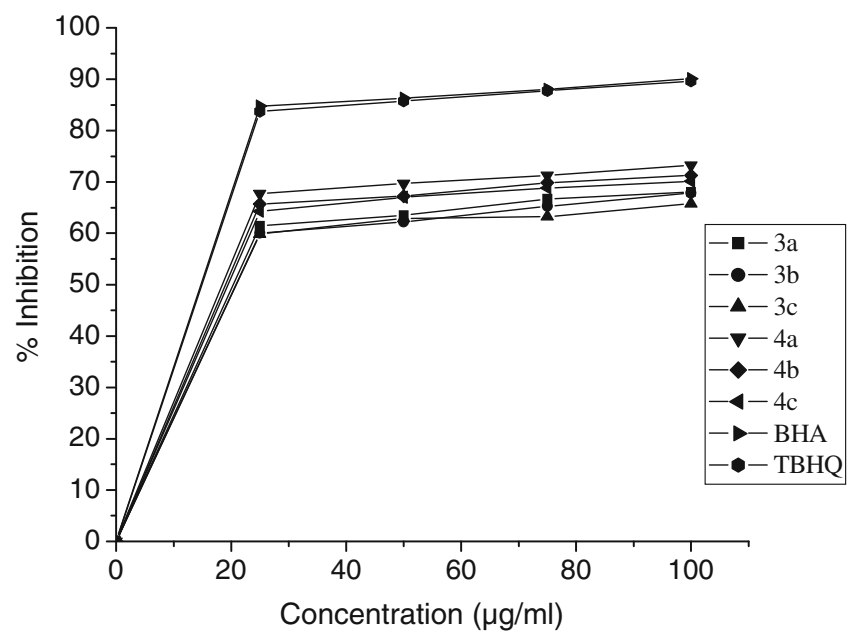

Figure 1. Reducing power of compounds 3 and 4.

in DMSO $(1 \mathrm{ml})$ were mixed with phosphate buffer ( $2.5 \mathrm{ml}, 0.2 \mathrm{~mol}, \mathrm{pH}=6.6)$ and potassium ferricyanide $(2.5 \mathrm{ml}, 1 \%)$. The mixture was incubated at $50^{\circ} \mathrm{C}$ for $20 \mathrm{~min}$. after which a portion $(2.5 \mathrm{ml})$ of trichloroacetic acid $(10 \%)$ was added to the mixture, which was then centrifuged for $10 \mathrm{~min}$. at $1000 \times \mathrm{g}$. The upper layer of solution $(2.5 \mathrm{ml})$ was mixed with distilled water $(2.5 \mathrm{ml})$ and $\mathrm{FeCl}_{3}(0.5 \mathrm{ml}, 0.1 \%)$, and then the absorbance at $700 \mathrm{~nm}$ was measured in a spectrophotometer. BHA, TBHQ and ascorbic acid (A. A) were used as standards.

\subsection{Radical scavenging activity (RSA) assay}

The free radical scavenging activity of 3-9 was carried out in the presence of the stable free radical DPPH following Hatano's method ${ }^{48}$ using

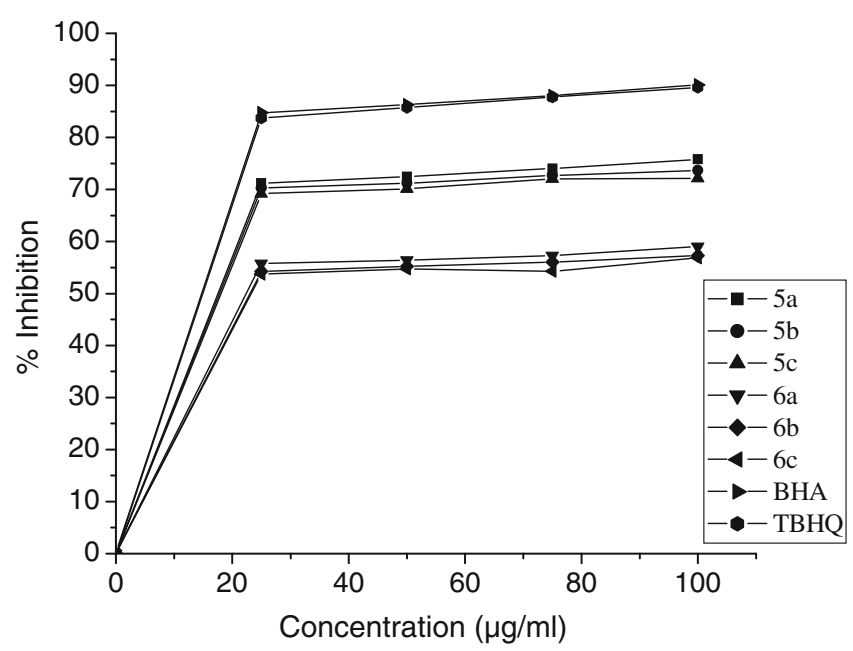

Figure 2. Reducing power of compounds 5 and 6. 


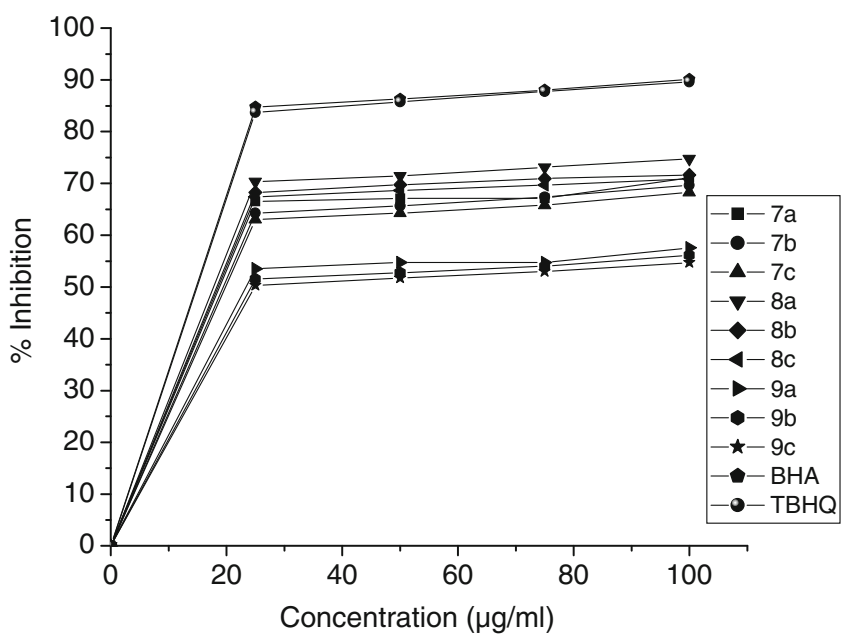

Figure 3. Reducing power of compounds 7, 8 and 9.

2-tert-butyl-4-methoxyphenol (butylated hydroxyl anisole, BHA), 2-(1,1-dimethylethyl)-1,4-benzenediol (2-tert. butyl hydroquinone, TBHQ) and ascorbic acid as standards. The radical scavenging activity (RSA) for methanolic solutions of compounds 3-9 at concentrations $25,50,75$ and $100 \mu \mathrm{g} / \mathrm{ml}$ containing freshly prepared DPPH solution $(0.004 \% \mathrm{w} / \mathrm{v})$ was carried out and compared with those of standards BHA and TBHQ. All the test analyses were performed on three replicates and results are averaged. The results in percentage are expressed as the ratio of absorption decrease of DPPH in the presence of test compounds and absorption of $\mathrm{DPPH}$ in the absence of test compounds at $517 \mathrm{~nm}$ using ELICO SL 171 Mini Spec spectrophotometer.

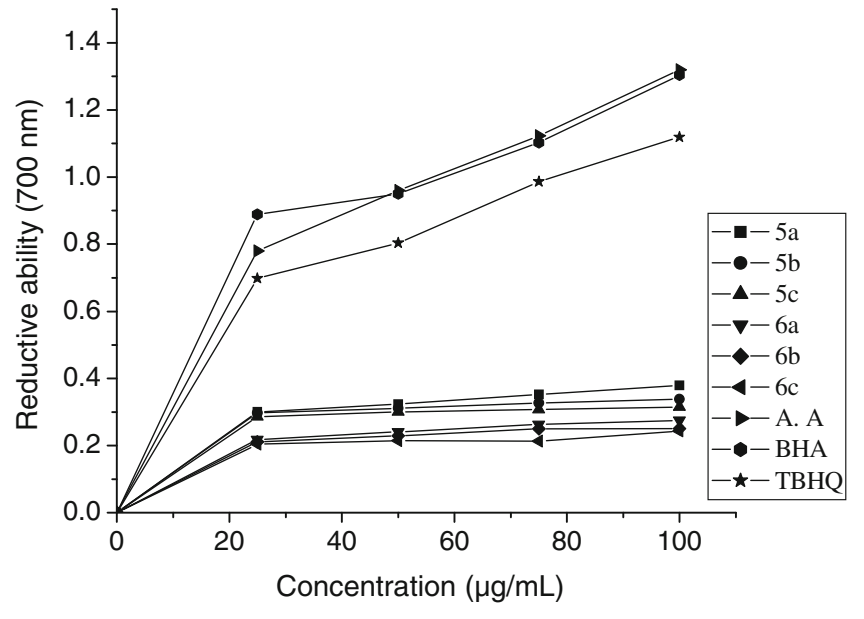

Figure 5. DPPH Radical scavenging activity of compounds $\mathbf{5}$ and $\mathbf{6}$.

The percentage scavenging activity of the DPPH free radical was measured using the following equation

$\%$ DPPH radical scavenging

$$
\begin{aligned}
= & \frac{\text { Absorbance of control-Absorbance of test sample }}{\text { Absorbance of control }} \\
& \times 100 .
\end{aligned}
$$

Antioxidant activity of these compounds was investigated by measuring the reducing power and radical scavenging effect of DPPH radicals. In reducing power assay, the presence of reducer (i.e., antioxidant) causes the reduction of $\mathrm{Fe}^{+3} /$ ferricyanide complex to ferrous form. The reducing power of the test

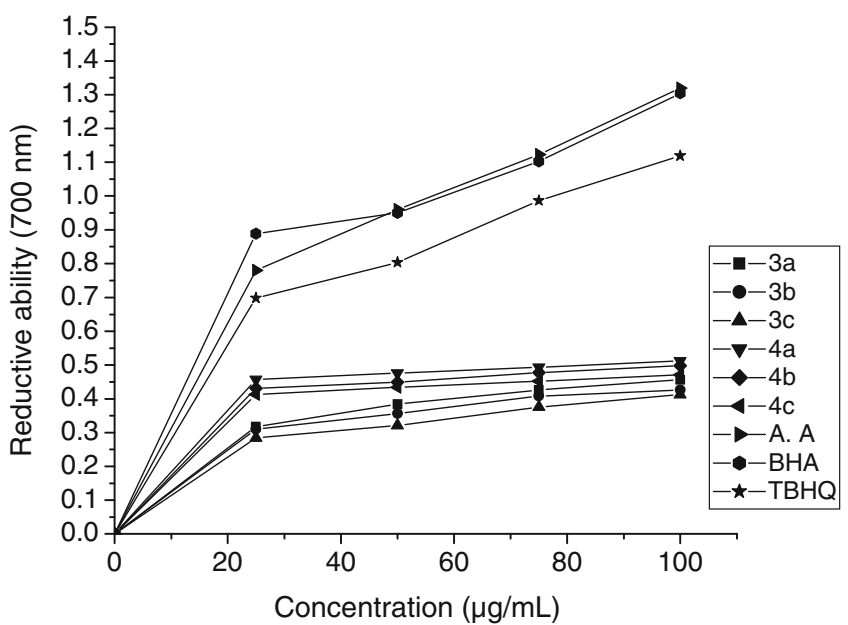

Figure 4. DPPH Radical scavenging activity of compounds 3 and $\mathbf{4}$.

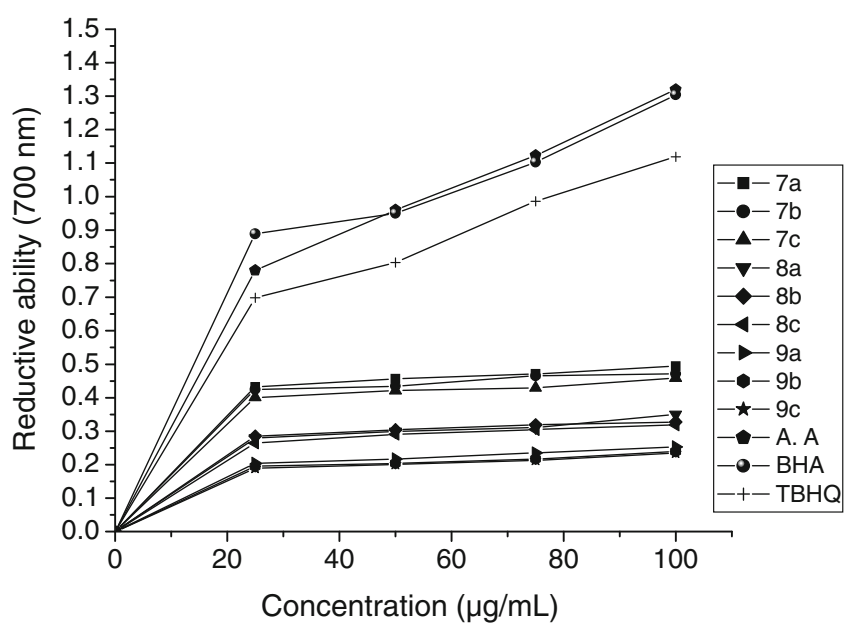

Figure 6. DPPH Radical scavenging activity of compounds 7, 8 and 9. 
compounds increases with increase in concentration. Compounds 3-9 exhibited very low absorption hence, the compounds were less active compared to standards used (figures 1-3). In case of radical scavenging activity, compounds 5 and $\mathbf{7}$ showed good percentage of inhibition (figures 4-6).

The probable mode of action of compounds 5 and 7 was illustrated in schemes 2,3 and 4 . In case of compound 5, two labile hydrogen (hydrogen of indole $\mathrm{NH}$ and other at position-2 in 1,3-thiazolidinone system) are available. One of these hydrogens could be donated to the DPPH free radical to form the stable DPPH molecule. The radical formed from compound 5 could be well-stabilized by resonance as shown in schemes 2 and 3. In case of compound 7, the hydrogen(s) of azomethine and methyl group at position- 6 of thienopyrimidine are much more acidic than the hydrogen of the indole NH. Hence, these could be easily donated to DPPH free radical and convert itself into the stable free radical, which could be well-stabilized by<smiles>[R]c1ccc2[nH]c(-c3ccccc3)c(C3SCC(=O)N3n3c(C)nc4sc(C)c(C)c4c3=O)c2c1</smiles><smiles>[R]c1ccc2c(c1)C([C@H]1SCC(=O)N1n1c(C)nc3sc(C)c(C)c3c1=O)C(c1ccccc1)=N2</smiles>

DPPH radical

Scheme 2. DPPH radical scavenging activity: Probable mode of action of compound $\mathbf{5}$ and stabilization of free radical formed after donating hydrogen of indole $\mathrm{NH}$. 
<smiles>[R]c1ccc2[nH]c(-c3ccccc3)c(C3SCC(=O)N3n3c(C)nc4sc(C)c(C)c4c3=O)c2c1</smiles>

Compound 5<smiles>O=[N+]([O-])c1cc([N+](=O)[O-])c(NN(c2ccccc2)c2ccccc2)c([N+](=O)[O-])c1</smiles>

DPPH radical

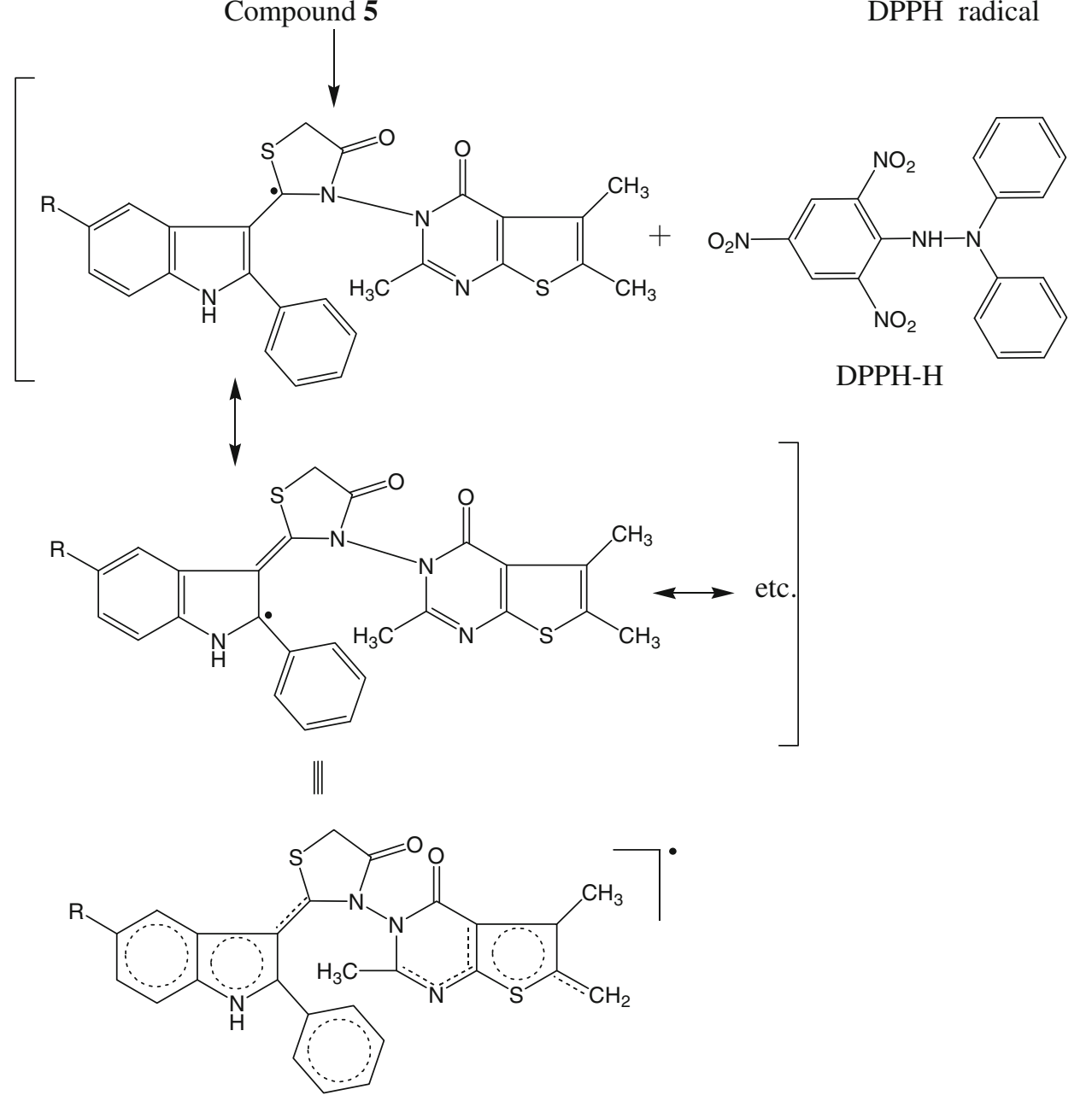

Scheme 3. DPPH radical scavenging activity: Probable mode of action of compound $\mathbf{5}$ and stabilization of free radical formed after donating hydrogen from thiazolidin-4-one system.

resonance as shown in scheme 4. Thus, compounds 5 and 7 could act as good hydrogen donors and antioxidant as compared to rest of the compounds tested. The same principle holds good for the reducing power assay of compounds $\mathbf{5}$ and $\mathbf{7}$.

\subsection{Antimicrobial assay}

The antimicrobial activities ${ }^{49}$ of the compounds prepared in this effort were evaluated using Pseudomonas aeroginosa (Gram negative bacteria), Staphylococcus aureus and Klebsiella pneumoniae (gram negative bacteria), Aspergillus oryzae, Aspergillus terrus and Aspergillus niger (fungi). An aliquot $0.1 \mathrm{ml}$ of each bacterial strain was on nutrient agar while $0.1 \mathrm{ml}$ of the fungal spore suspension was spread on potato dextrose agar (PDA). An agar-well diffusion test was performed in each case. In these tests, $6 \mathrm{~mm}$ wells were produced by using a sterile cork borer and each well was then inoculated with $100 \mu \mathrm{L}$ of each key substance in 
<smiles>[R]c1ccc2[nH]c(-c3ccccc3)c(/C=N/n3cnc4sc(C)c(C)c4c3=O)c2c1</smiles>

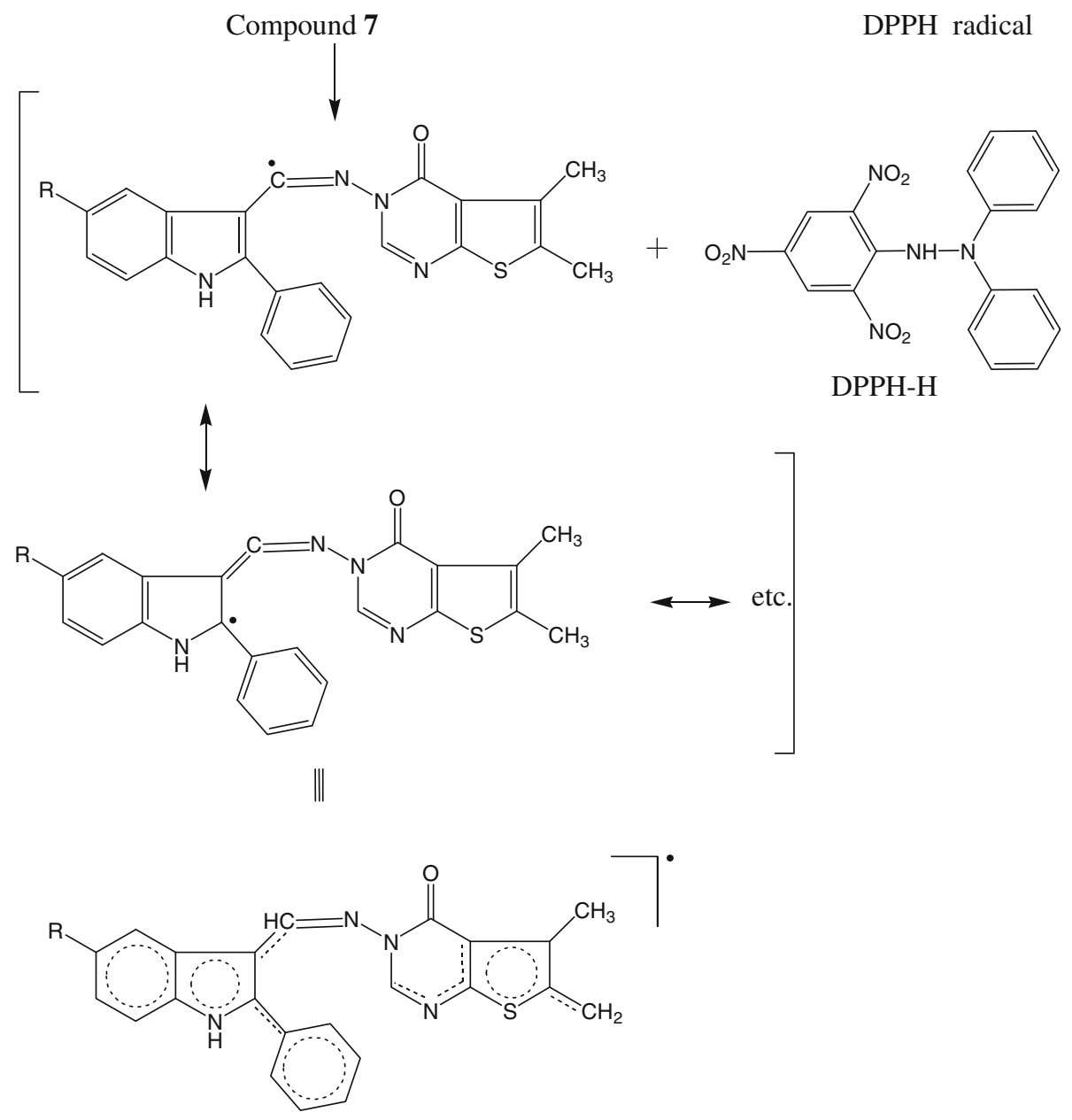

Scheme 4. DPPH radical scavenging activity: Probable mode of action of compound 7 and stabilization of free radical formed after donating hydrogen radical.

DMF, resulting in a final concentration of $1000 \mu \mathrm{g} / \mathrm{ml}$. Nutrient agar plates were incubated at $37^{\circ} \mathrm{C}$ for $24 \mathrm{~h}$ while the PDA plates incubated at $25^{\circ} \mathrm{C}$ for 72 h. The zone of inhibition around the well was determined. Gentamycin and flucanozole were used as the reference antibacterial and antifungal agents, respectively.

In antimicrobial activity, compounds 3a, 5a, 6a and 9a showed good zone of inhibition against $S$. Aureus, compounds 3a, 6a and 9a exhibited maximum zone of inhibition against $P$. Knemonia. Where as in case of antifungal activity, compounds 5a, 6a, 9a and 9b produced maximum zone of inhibition against $A$. Oryzae. Compound 9a exhibited maximum inhibitory growth against $A$. Terrus and compounds 5a and $\mathbf{6 a}$ shown maximum zone of inhibition against A. Nizer (table 1).

These results suggest that, compounds having chloro substituent were much more capable of inhibiting the growth of organism compared to other compounds. This may be due to the electronegative nature of the chlorine atom in the position-5 of indole nucleus in addition to the different heterocyclic systems present in the individual compounds. 
Table 1. Antimicrobial activities of synthesized compounds (3-9).

\begin{tabular}{|c|c|c|c|c|c|c|}
\hline \multirow{2}{*}{ Comp. No. } & \multicolumn{3}{|c|}{ Antibacterial activity (zone of inhibition in $\mathrm{mm}$ ) } & \multicolumn{3}{|c|}{ Antifungal activity (zone of inhibition in $\mathrm{mm}$ ) } \\
\hline & S. aureus & P. aeruginosa & K. pneumonia & A. oryzae & A. terrus & A. nizer \\
\hline $3 \mathbf{a}$ & 14 & 10 & 14 & 12 & 12 & 10 \\
\hline $3 \mathbf{b}$ & 13 & 09 & 10 & 09 & 10 & 11 \\
\hline $3 c$ & 12 & 13 & 09 & 08 & 09 & 12 \\
\hline $4 \mathbf{a}$ & 11 & 12 & 12 & 08 & 07 & 10 \\
\hline $4 b$ & 10 & 09 & 10 & 10 & 10 & 10 \\
\hline $4 c$ & 10 & 08 & 09 & 11 & 12 & 09 \\
\hline $5 \mathbf{a}$ & 14 & 12 & 13 & 13 & 11 & 13 \\
\hline $5 b$ & 12 & 10 & 11 & 12 & 12 & 10 \\
\hline $5 c$ & 13 & 09 & 10 & 09 & 10 & 11 \\
\hline $6 \mathbf{a}$ & 14 & 13 & 14 & 13 & 12 & 13 \\
\hline $6 \mathbf{b}$ & 13 & 12 & 13 & 09 & 10 & 10 \\
\hline $6 c$ & 12 & 11 & 11 & 12 & 10 & 12 \\
\hline $7 \mathbf{a}$ & 12 & 10 & 09 & 10 & 11 & 13 \\
\hline $7 b$ & 09 & 10 & 08 & 09 & 12 & 09 \\
\hline 7c & 08 & 07 & 08 & 07 & 10 & 10 \\
\hline $8 \mathbf{a}$ & 13 & 12 & 12 & 10 & 10 & 10 \\
\hline $8 b$ & 12 & 10 & 13 & 12 & 09 & 11 \\
\hline $8 c$ & 11 & 10 & 11 & 11 & 10 & 11 \\
\hline $9 \mathbf{a}$ & 14 & 13 & 14 & 13 & 13 & 12 \\
\hline $9 b$ & 13 & 09 & 10 & 13 & 11 & 12 \\
\hline $9 c$ & 12 & 12 & 10 & 12 & 12 & 10 \\
\hline Gentamycin & 15 & 16 & 15 & - & - & - \\
\hline Flucanozole & - & - & - & 14 & 15 & 14 \\
\hline
\end{tabular}

\section{Conclusion}

In general, it was found that the compounds having chloro substitution along with the thiazolidine and azetidinone systems exhibited good antioxidant and antimicrobial activities.

\section{Acknowledgements}

The authors are thankful to the Chairman, Department of Chemistry, Gulbarga University, Gulbarga, for providing laboratory facilities. We are also thankful to the Director, Indian Institute of Technology, Chennai for providing spectral data.

\section{References}

1. Valko M, Izakovic M, Mazur M, Rhodes $\mathrm{C} \mathrm{H} \mathrm{J}$ and Telser J 2004 Mol. Cell. Biochem. 26637

2. Dröge W 2002 Physiol. Rev. 8247

3. Valko M, Rhodes C J, Moncol J, Izakovic M and Mazur M 2006 Chem. Biol. Interact. 1601

4. Valko M, Leibfritz D, Moncol J, Cronin M T D, Mazur M and Telser J 2007 Int. J. Biochem. Cell Biol. 3944
5. Soler C, Espin J C and Wichers H 2000 Phytochem. Anal. 111

6. Frankel E D 2007 Antioxidants in food and biology. Facts and fiction (Bridgwater, England: The Oily Press) p. 1

7. Silva F M, Borges F, Guimaraes J J, Lima F C, Matos C and Reis C J 2000 Agric. Food Chem. 482122

8. Shahidi F, Janitha P K and Wanasundara P D 1992 Crit. Rev. Food Sci. 3267

9. Tan D X, Chen L D, Poeggeler B, Manchester L C and Reiter R J 1993 J. Endocr. 157

10. Sreejith P, Beyo R S, Divya L, Vijayasree A S, Manju $\mathrm{M}$ and Oommen O V 2007 Indian J. Biochem. Biophys. 44164

11. Chen I, Safe S and Jeldanes L 1996 Biochem. Pharmacol. 511069

12. Suzen S and Buyukbingol E 2000 Il Farmaco. 55 246

13. Buyukbingol E, Suzen S and Klopman G 1994 Il Farmaco. 49443

14. Lieberman P M, Wolfle A, Felsne P, Hofe D and Schauenstien K 1997 Int. Arch. Allergy Immunol. 112 203

15. Page D, Yang H, Brown W, Walpole C, Fleurent M, Fyfe M, Gaudreault F and Onge S S 2007 Bioorg. Med. Chem. Lett. 226183

16. Chyan Y J, Poeggler B, Omar R A, Chain D G, Frangione B, Ghiso J and Pappolla M A 1999 J. Biol. Chem. 27421937 
17. Sudhir Kumar B and Ashok K 2008 Euro. J. Med. Chem. 432323

18. Dore K, Dubus S, Ho H A, Levesque I, Brunette M, Corbeil G, Boissinot M, Boivin G, Bergeron M, Boudreau D and Leclerc M 2004 J. Am. Chem. Soc. 126 263

19. Jarvest R L, Pinto I L, Ashman S M, Dabrowski C E, Fernandez A V, Jennings L J, Lavery P and Taw D G 1999 Bioog. Med. Chem. Lett. 9443

20. Shuichi F and Nobuhiro S, Japan Pat. 0178,780 (Cl. A61K45/00), 25 Oct 2001, JP Appl. 2000/112, 046, 13 Apr 2000; Chem. Abstr. 2001135 313627w

21. Bothaina A, Manal M K and Maha Zeinab M F 2006 J. Chinese Chem. Soc. $\mathbf{5 3} 403$

22. Aymn E R, Ahmed H S, Randa E, Abdel M and Wael A E 2010 Synthetic Commun. 401149

23. Cantello B C, Cawthorne M A, Cottam G P, Du P T, Haigh D, Kindley R M, Lister C A, Smith S A and Thurlby P L 1994 J. Med. Chem. 373977

24. Kucukguzel S G, Oruc E E, Rollas S, Sahin F and Ozbek A 2002 Eur. J. Med. Chem. 37197

25. Capan G, Ulusoy N, Ergenc N and Kiraz M 1999 Monatsh. Chem. 1301399

26. Bhatt J J, Shah B R, Shah H P, Trivedi P B, Undavia N $\mathrm{K}$ and Desai N C 1994 Indian J. Chem. 33B 189

27. Bhat A R and Shetty S 1987 J. Indian Pharm. Sci. 194

28. Ragab F A, Eid N M and El-Tawab H A 1997 Pharmazie 52926

29. De Lima J G, Perrissin M, Chantegrel J, Luu-Duc C, Rousseau A and Narcisse G 1994 Arzneim. Forsch. Drug Res. 44831

30. Andreani M, Rambaldi A, Locatelli A, Leoni R, Bossa M, Chiericozzi I, Galatulas G and Salvatore 1993 Eur. J. Med. Chem. 28825

31. Barreca M L, Chimirri A, De Luca L, Monforte A M, Monforte P, Rao A, Zappala M, Balzarini J, De Clercq E, Pannecouque C and Witvrouw M 2001 Bioorg. Med. Chem. 111793
32. Rao A, Chimirri A, De Clercq E, Monforte A M, Monforte P, Pannecouque C and Zappala M 2002 Farmaco 57747

33. Taanabe Y, Yamamoto H, Murakami M, Yanagi K, Kubota Y, Okumura H, Sanemitsu Y and Suzukamo G 1995 J. Chem. Soc. Perkin Trans-I 935

34. Diurno M V, Mazzoni O, Correale G, Monterrrey I G, Calignano A, La Rana G and Bolognese A 1999 Il Farmaco. 54579

35. Boschelli D H, Connor D T, Kuipers P J and Wright C D 1992 Bioorg. Med. Chem. Lett. 2705

36. Monforte M T and Taviaano M F 2001 Bioorg. Med.Chem. Lett. 112791

37. Kidwai M, Sapra P and Bhushan K R 1999 Curr. Med. Chem. 6195

38. Deshmukh A R, Bhawal B M, Krishnaswamy D, Govande V V, Shinkre B A and Jayanthi A 2004 Curr. Med. Chem. 111889

39. Diurno M V, Mazzoni O, Piscopo E and Bolognese A 1992 Il Farmaco. 47239

40. Alcaide B and Almendros P 2004 Curr. Med. Chem. 11 1921

41. Singh S G and Boycie J M 2005 Il Farmaco. 60727

42. Vaccaro W D, Sher R, Jr and Davis H R 1998 Bioorg. Med. Chem. Lett. 8319

43. Saundane A R, Manjunatha Y and Prabhakar W 2009 Heterocycl. Commn. 15303

44. Saundane A R and Veeresh Sharma P M 2004 Indian J. Heterocycl. Chem. 13275

45. Ameen A A, Mohamed F E and Farid A B 2010 Acta Pharm. 60311

46. Hiremath S P, Biradar J S and Purohit M G 1982 Indian J. Chem. 21B 249

47. Hatano T, Kanawa H, Yasuhara T and Okuda T 1988 Chem. Pharm. Bul. 362090

48. Oyaizu M 1986 Japan Nutri. 44307

49. Indian pharmacopoeia, Government of India, $3^{\text {rd }}$ ed. NewDelhi Appendix IV 198590 